\title{
Nano Drug Delivery Study of Anticancer Properties on Ginger using QM/MM Methods
}

\section{FARNOUSH NAGHSH}

\author{
Department of Chemistry, Tehran Science and Research Branch, \\ Islamic Azad University, Tehran, Iran. \\ *Corresponding author E-mail: F.naghsh@srbiau.ac.ir \\ http://dx.doi.org/10.13005/ojc/310156
}

(Received: December 18, 2014; Accepted: January 24, 2015)

\begin{abstract}
Ginger is a one of the most important foods which as an anticancer drug. It is well-known for its ability to shrink tumors. The anti-cancer properties were observed in addition to ginger's role in reducing inflammation, as well as being a rich source of life-enhancing antioxidants. Ginger has long been used in traditional medicine as a cure for some diseases including inflammatory diseases ${ }^{1}$.Ginger contains active phenolic compounds such as gingerol, paradol and shogaol that have antioxidant ${ }^{2}$, anti-cancer ${ }^{3}$, anti-inflammatory ${ }^{4}$, anti-angiogenesis ${ }^{5}$ and anti-artherosclerotic properties $^{6}$ (Fig.2). In the present work, we investigated the potential anti-inflammatory and anticancer effects of ginger extract including gingerol, andshogaol jointed to nanotubeas dug delivery technics. So, we have used Gussian 98 methods for calculation via (B3LYP-MP2-) with 6-31g*, basis sets. We has also studied NMR by changing the substituents in ginger for analyzing its properties.
\end{abstract}

Key words: Ginger, gingerol, paradol, shogaol, anti cancer, anti-inflammatory, anti artherosclerotic, antioxidants.

\section{INTRODUCTION}

Man's acquaintance with the medicinal properties of plants is of great antiquity. Even the higher mammals are said to be aware of the curative aspects of plant kingdom. Plants have been used in a number of systems of medicines in most countries. India is well known as the 'Emporium of Medicinal Plants'. The use of plants to treat various diseases in India dates back to the times of RigVeda (3500 to 1800 B.C.). Later, the monumental Ayurvedic works like Charaksamhita and Sushrutasamhita followed by other Ayurveda and Siddha treatises have incorporated nearly 700 plant drugs entering into several medicinal preparations used in the management of health care. In fact these systems have been in practice even in remote areas of our country for centuries 1 . Ginger consists of the 
fresh or dried roots of Zingiberofficinale. The English botanist William Roscoe (1753-1831) gave the plant the name Zingiberofficinale in an 1807 publication. The ginger family is a tropical group especially abundant in Indo-Malaysia, consisting of more 1200 plant species in 53 genera. The genus Zingiber includes about 85 species of aromatic herbs from East Asia and tropical Australia. The name of the genus, Zingiber, derives from a Sanskrit word denoting "horn-shaped," in reference to the protrusions on the rhizome 2, 3 . Zingiberofficinalis Roscoe, commonly known as ginger belongs to family Zingiberaceae is cultivated commercially in India, China, South East Asia, West Indies, Mexico and other parts of the world. It is consumed worldwide as a spice and flavoring agent and is attributed to have many medicinal properties ${ }^{1-6-7-10}$.

The British Herbal Compendium reported its action as carminative, anti- emetic, spasmolytic, peripheral circulatory stimulant and antiinflammatory ${ }^{4}$. The oil of ginger is a mixture of constituents, consisting of monoterpenes (phellandrene, camphene, cineole, citral, and borneol) and sesquiterpenes (zingiberene, zingiberol, zingiberenol, ß-bisabolene, sesquiphellandrene, and others). Aldehydes and alcohols are also present 5, 6. A numeral of commercial variety of ginger exists. Nigerian Ginger is darker in color, minute size and more pungent taste. Cochin Ginger is habitually larger, well scraped, contains more starch and breaks with a shorter fracture. African Ginger is darker in color, more pungent in taste and less flavor than Jamaica Ginger. Ginger plant is propagated by rhizome cuttings each bearing a bud. The pieces of rhizome are planted in holes during March and April in a well- drained clayey soil. In December or January rhizomes are unruffled. Ginger requires a warm and humid atmosphere. A well distributed rainfall is required for its cultivation. If the area is getting fewer rainfalls, the crop needs habitual irrigation ${ }^{7} .^{1-11-15-17}$

The major pungent compounds in ginger, from studies of the lipophilic rhizome extracts, have yielded potentially active gingerols, which can be converted to shogaols, zingerone, and paradol that have antioxidant anti-cancer), antiinflammatory, angiogenesis), and anti-atherosclerotic properties).
Ginger has been known to comprise of the following nutrients: calcium, carbohydrate, dietary fiber, iron, magnesium, manganese, potassium, protein, selenium, sodium, and vitamin, C, E and B6. A fresh ginger contains $80.9 \%$ moisture, $2.3 \%$ protein, $0.9 \%$ fat, $1.2 \%$ minerals, $2.4 \%$ fiber and $12.3 \%$ carbohydrates. The composition varies with the type, varieties and agronomic condition and storage condition ${ }^{4}$ consumption of fruits, vegetables, and whole grains may reduce cancer risk in some individuals. This association has been attributed to these foods being rich sources of numerous bioactive compounds (Milner,2004). Bioactive components present in fruits and vegetables can prevent carcinogenesis by blocking metabolic activation, by increasing detoxification, or by providing alternative targets for electrophilic metabolites (kuo et al., 2005). Numerous constituents of plant foods, including flavonoids (such as quercetin, rutin, and genistein), phenols (such as curcumin, epigallocatin-3-gallate and resveratrol), isothiocyanates, allyl sulfur compounds, indoles, and selenium have been found to be potent modulators of detoxification enzymes in vitro and in preclinical models (Milner ,2001 and Keum et al., 2004). The effect of plant extracts as antitumors was widely studied due to their low toxicity and side effect. The inhibition of ascites tumor cells by Nigella sativa seed extracts was investigated (Musa et al., 2004). Willow extracts antitumor activity which is due to the presence of Salicin (Zahran et al., 2005). Curcuma longa extracts and active constituents have a potential role in the prevention of cancer and the management of infectious and chronic diseases (Ahmad et al., $2008^{2}$.

Many herbs and spices are known to possess an array of biochemical and pharmacological activities in relation to its potential antiinflammatoryproperties; ginger extract has been shown to inhibit the activation of TNF-á and cyclooxygenase-2 expression during in vitro studies of human synoviocytes. Ginger extract possesses antioxidative characteristics, since it can scavenge superoxide anion and hydroxyl radicals.). Gingerol from ginger inhibit, at high concentrations, ascorbate / ferrous complex induced lipid peroxidation in rat liver microsomes ${ }^{4}$. 
Tumor promotion is closely linked to inflammation and oxidative stress; so compounds that exhibit anti-inflammatory and/or antioxidant properties could acts as anticarcinogenic agent (Masuda et al., 2004).Some phenolic substances present in ginger(Zingiberofficinale Roscoe, Zingiberaceae), generally, possess strong antiinflammatory, anti-oxidative and anti-mitotic properties and exert substantial anti-carcinogenic and anti-mutagenic activities (Surh, 2002 ; Bode, 2003; Kim et al.,2005a ; Vijayapadma et al., 2007 and Choudhury et al., 2010)².

In Saudi Medical Journal, the authors report that both triglycerides and total cholesterol decreased significantly from baseline in the treatment compared with the placebo group. LDL cholesterol was reduced and HDL cholesterol was increased in the treatment group compared with placebo, but these changes were not significant. Furthermore, ginger acts as a hypolipidemic agent in cholesterol-fed rabbits Feeding rats with ginger significantly elevated the activity of hepatic cholesterol-7a-hydroxylase, the rate-limiting enzyme in bile acids biosynthesis, thereby stimulating cholesterol conversion to bile acids, resulting in elimination of cholesterol from the body ${ }^{3}$ ( According to one study oral administration of $170 \mathrm{mg} / \mathrm{kg}$ zingerone may reduce the body weight, blood glucose level and prevent the fat storage through increasing norepinephrin-induced lipolysis in adipocytes. There was also distinct decrease in lipid per oxidation and enhancement of fibrinolytic activity in ginger treated animals. Authors suggested the protection was probably because of its free radical scavanging, prostaglandin inhibitory and fibri properties. Tea is also reported to have multiple pharmacological actions and improved health related quality of life. It acts both as primary as well as secondary antioxidant by sequestration of metallic ion and by scavenging active oxygen species. Several epidemiological studies have demonstrated an inverse relationship between tea consumption and cholesterol. The tea catechin contains Epigallocatechingallate (EGCG) and EGC which were found to inhibit intestinal glucose transporter SGLTI,

Including its effect on controlling blood sugar.Ingestion of extract of tea in rats has significantly decreased plasma cholesterol and triglyceride concentrations and the ratio of low and very low density lipoprotein cholesterol concentrations to high density lipoprotein cholesterol concentrations. Tea polyphenols also increase fecal excretion of total lipids and cholesterol in rodents. One study demonstrated that the addition of five servings of tea per day to an NCEP Step I-type diet appreciably reduces total and LDL cholesterol in mildly hypercholesterolemic volunteers. Tea extracts were found to exert rapid normalization of blood glucose levels within three weeks on streptozotocin induced Diabetes in rats. Ginger and Tea both has been studied extensively in animal and in vitro models separately, however, their potential effects in combination have not yet been studied in humans. Since both Tea and Ginger are involved in lowering the lipid profile, these together can be used to see the cumulative effect on lipid profile, glucose level and insulin resistance ${ }^{3}$.

In addition chemotherapy with plantderived compounds or dietary phytochemicals has emerged as an accessible and promising approach to cancer control and management (Surh, 2003). A growing trend among some cancer patients is to combine conventional therapy with some form of complementary therapy (Vapiwala et al., 2006). These diverse pharmacological activities of their major principles have already been confirmed (Surh et al., 2002). Several lines of evidence suggest that 6 -gingerol is effective in the

Table 1:

\begin{tabular}{lccccc}
\hline Molecule & E HF Kcal/mol & $\begin{array}{c}\text { Dipol } \\
\text { Totally }\end{array}$ & $\begin{array}{c}\text { Dipol Totally } \\
\text { calculated }\end{array}$ & $\begin{array}{c}\text { Gap ENERGY } \\
\text { Kcal/mol }\end{array}$ & $\begin{array}{c}\text { Determinan } \\
\text { Distance Matrix }\end{array}$ \\
\hline a & -648531.4978 & & & -115.5121746 & $-1.27621 \mathrm{E}+15$ \\
b & -439321.3073 & 3.1220 & -117.8140363 & -2306040772 \\
c & -597129.262969661 & 3.7202 & & -95.5942 & $-3.5031 \mathrm{E}+14$ \\
\hline
\end{tabular}


我空

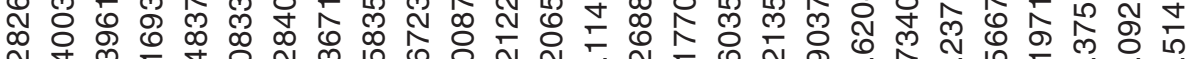

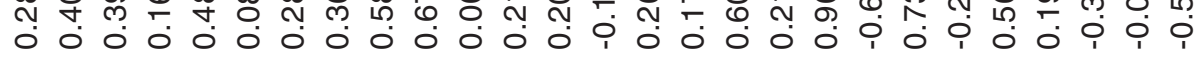

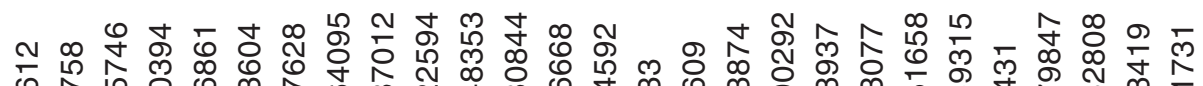
ঢ.

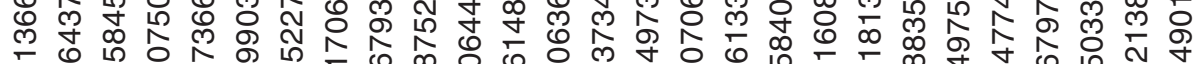

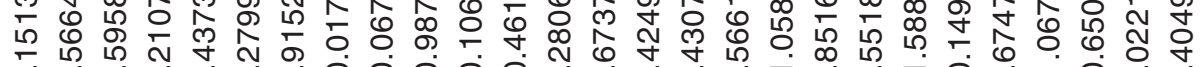
-

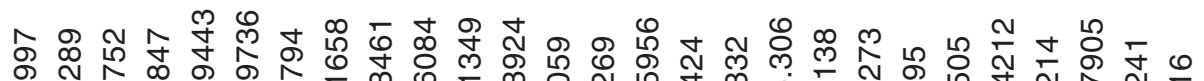
足 ๗

ᄂ స়

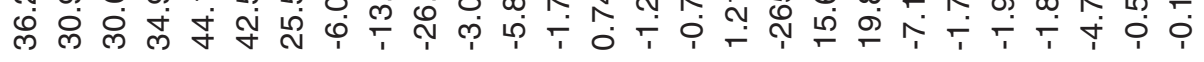

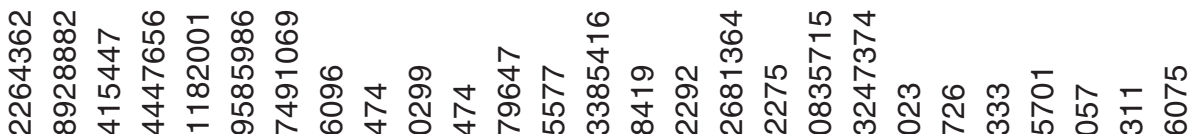

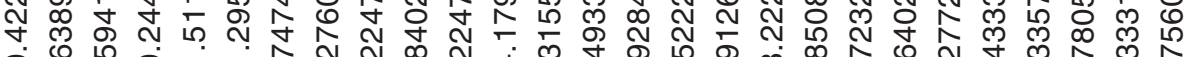
品

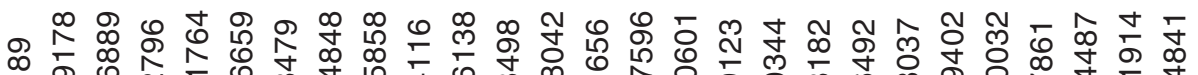

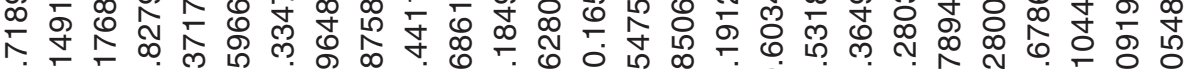

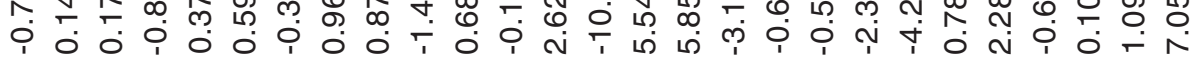

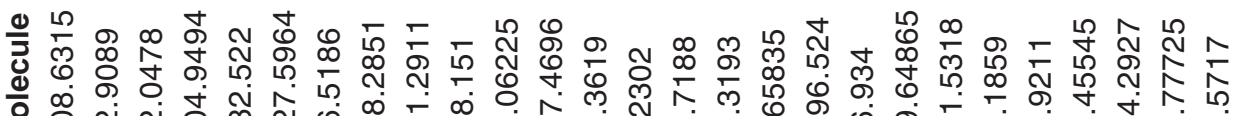

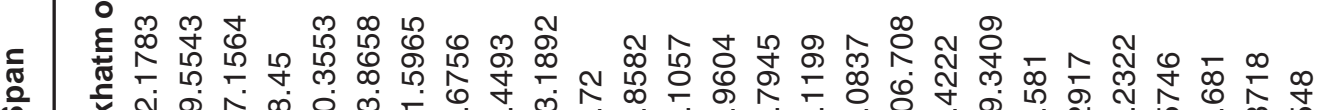
竞 $\subseteq$

总-

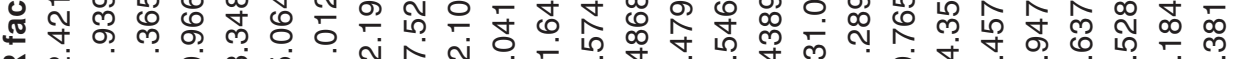

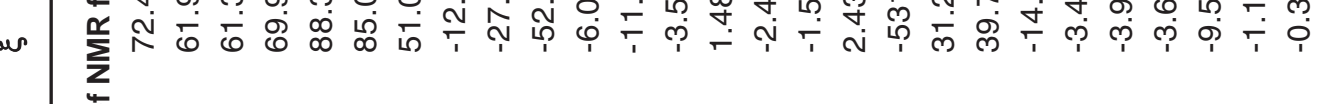
4

.는 ब西 


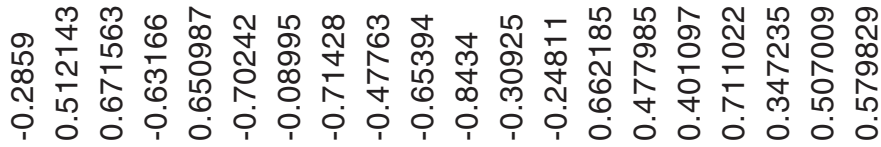

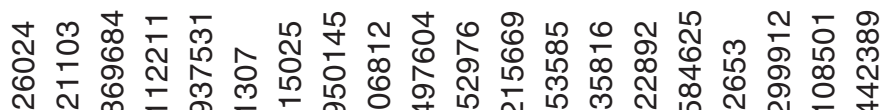

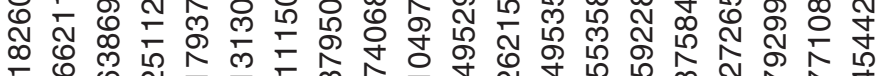
全

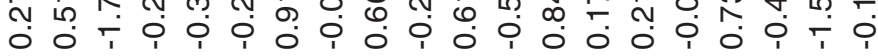

舟 品

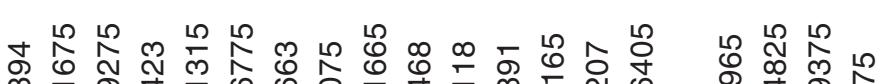
ग) 1

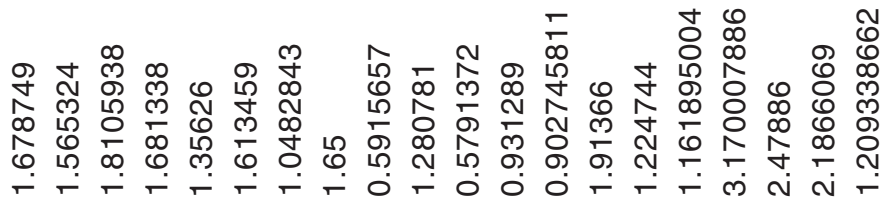

为 N

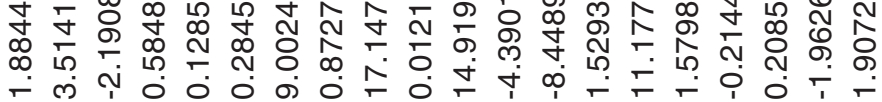

郘

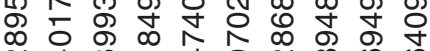

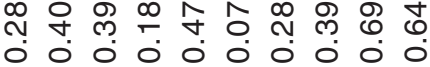

旅空 N

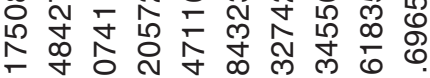

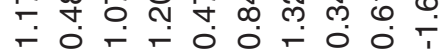

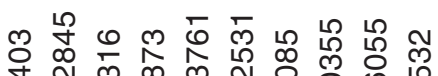

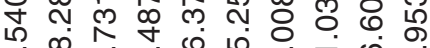
बำ

เ ᄂ

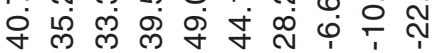

시료

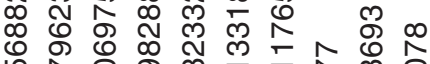
송용

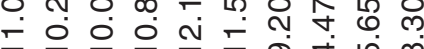

赵 命 ○

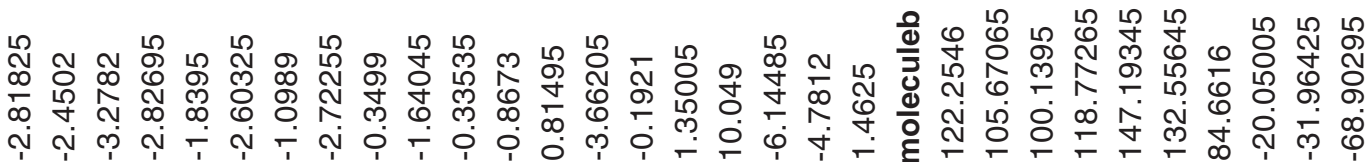

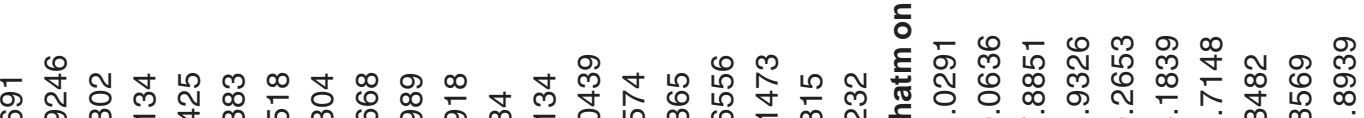
ஸ்

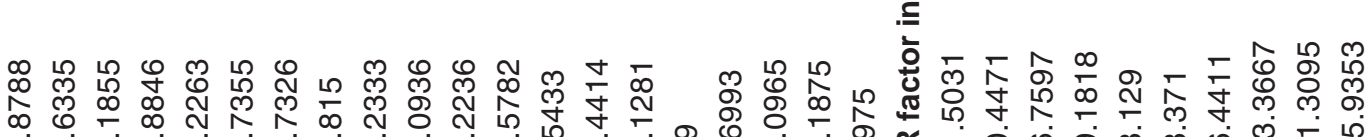
萍 $\sum_{0}^{\circ}$

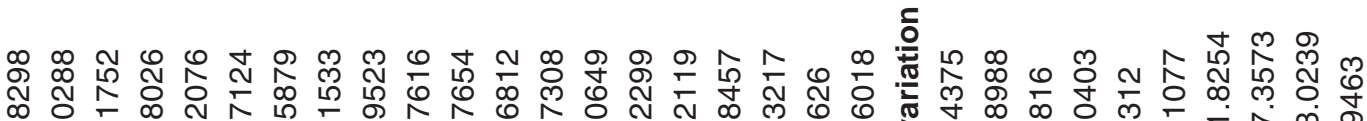
N 


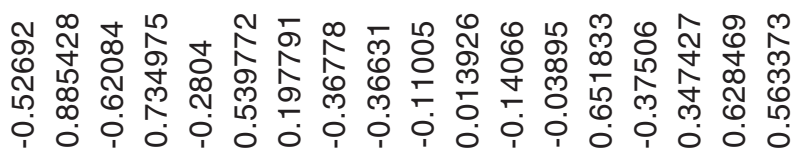

๒ ษ

品 กิ

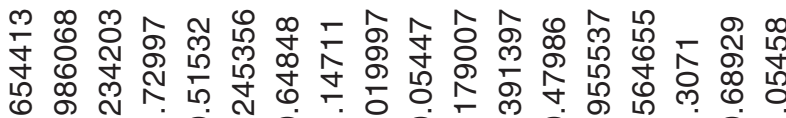
ભ

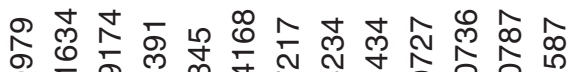
品 का

స กั 단 壬

\ั M N חల

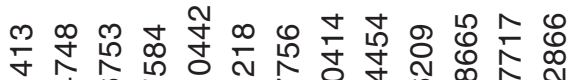

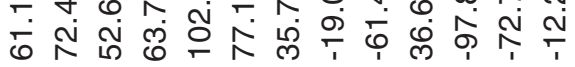

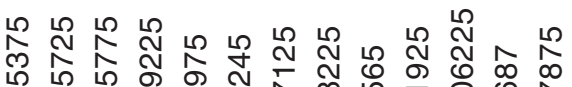

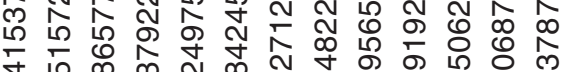
守

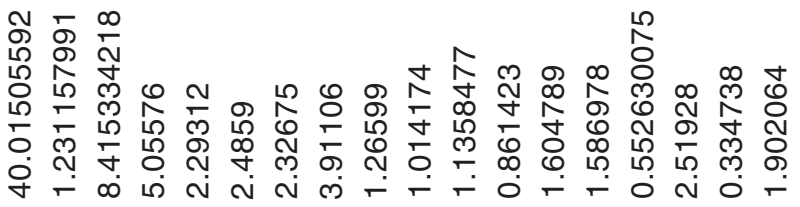

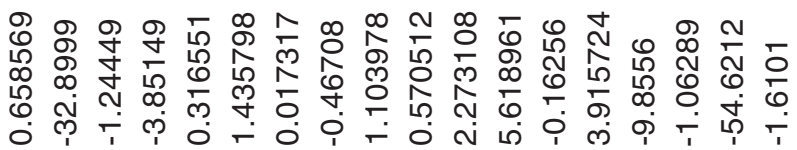

న ㄸ ᄃ $\mp$ ம œ ๙

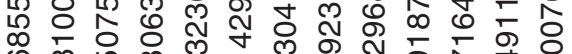
年

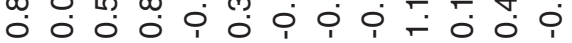

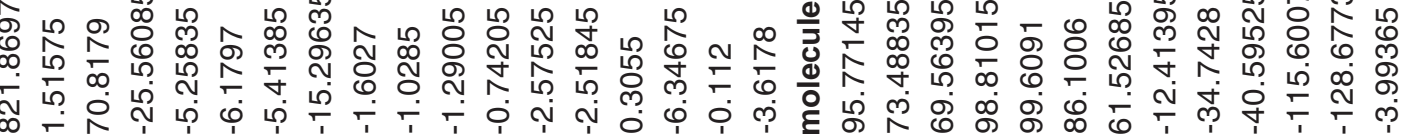

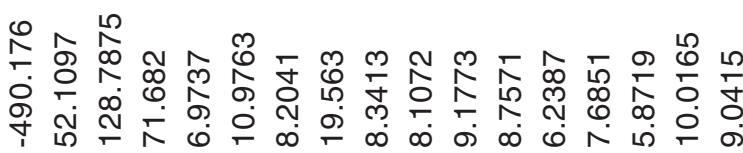
б ह กำ

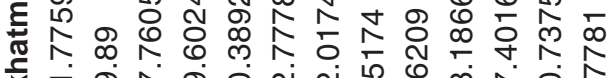
总 莳 代

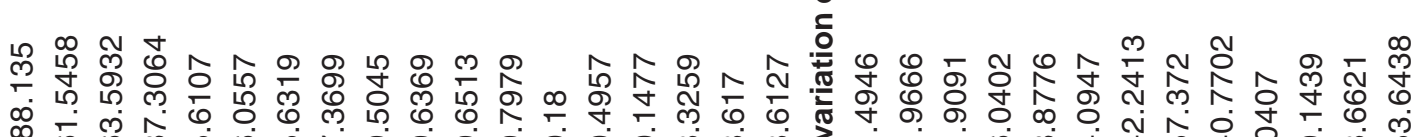
代 


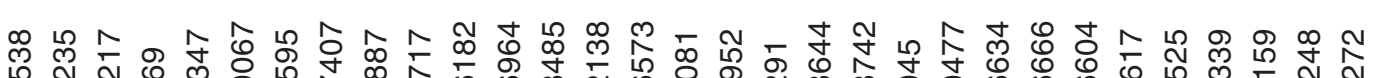
员

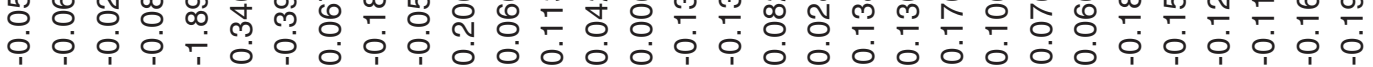

đ్ర

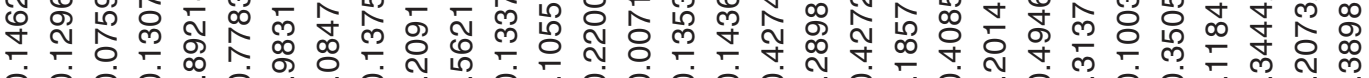

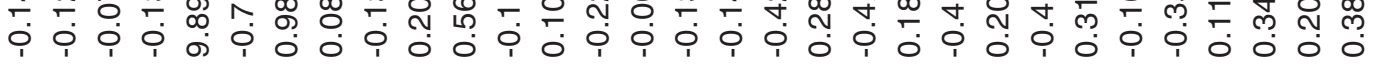

ஜ 㲾 m m

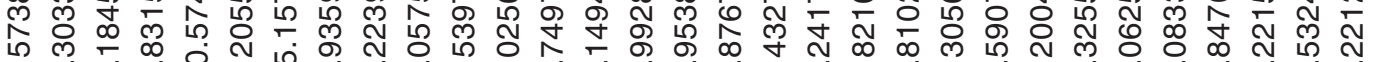


ษ

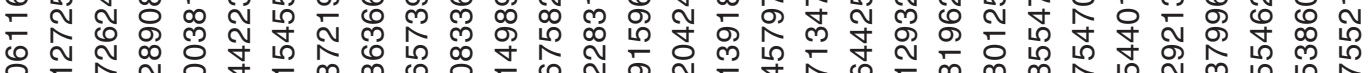

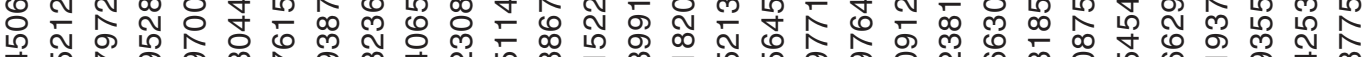
年 ம்

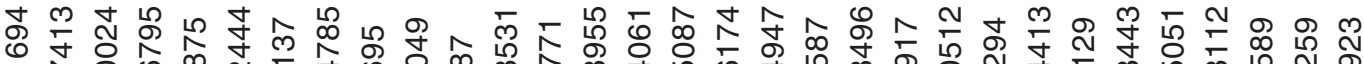

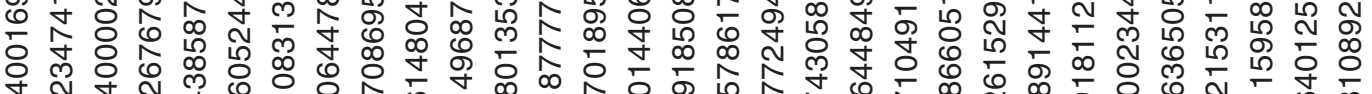

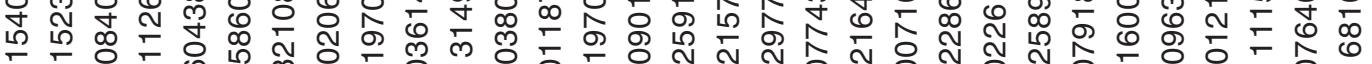

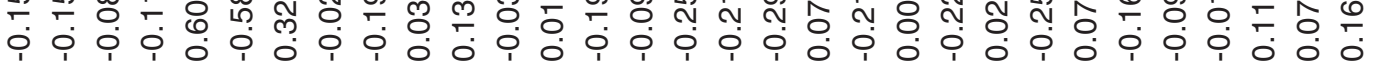

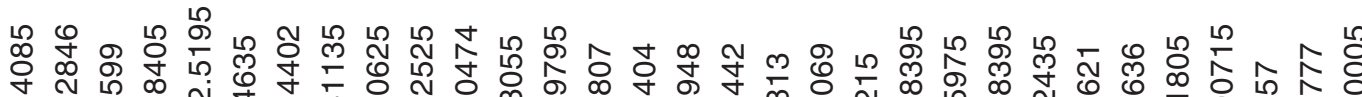
寸 N

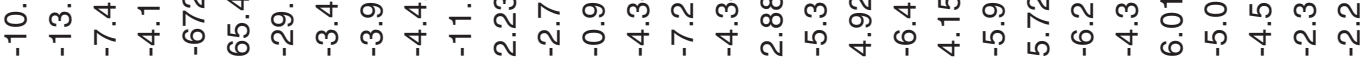

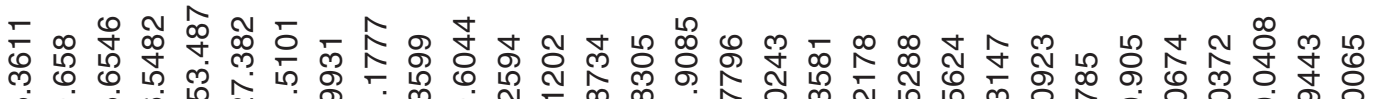

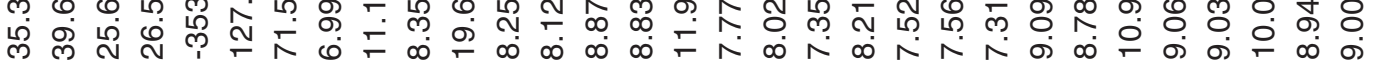

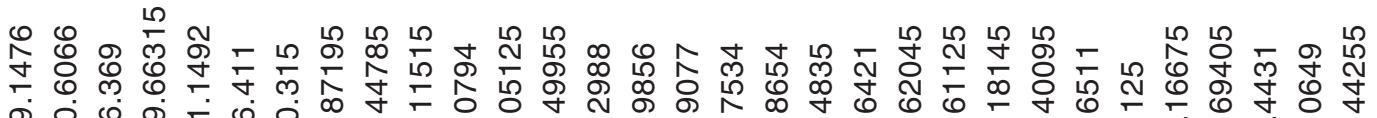
官

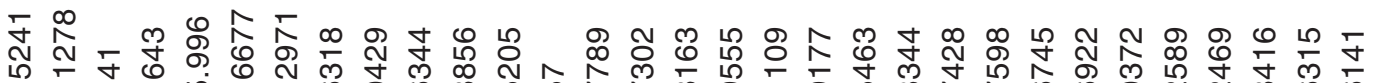

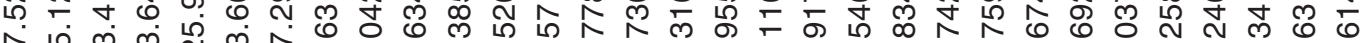
占 
suppression of the transformation, hyperproliferation, and inflammatory processes that initiate and promote carcinogenesis, as well as the later steps of carcinogenesis, the angiogenesis and metastasis (Suzuki et al., 1997; Bode et al., 2001; Kim et al., 2005a: 2005b; Lee et al., 2008). It is regarded as a promising chemopreventive dietary agent exhibiting inhibition of cyclooxygenase and lipoxygenase activities (Kiuchi et al., 1982: 1992; Huang et al., 1991), apoptosis induction (Lee et al., 1998; Chauhan, 2002), and anti-tumorigenic effects (Park et al., 1998; Surh et al., 1999). The pungent vallinoids of ginger, [6]-gingerol and [6]-paradol, exhibit antiproliferation activity in liver, pancreatic, prostate, gastric, and leukemia cancer cells (Lee et al., 1998; Chen et al., 2007; Shukla and Singh, 2007). Furthermore, [6]-shogaol has also been shown to exhibit anticancer activities against breast cancer, anti-proliferation activity (through disruption of microtubule network of non-small lung epithelium cancer) (Choudhury et al., 2010), and anti-invasion on human hepatocellular cell (Weng et al. 2010). With this motivationwe start this present study.

\section{EXPERIMENTAL}

As with all the previous in this study first time we have prepared 3 molecule gingerol, paradol and shogaolin gussview.

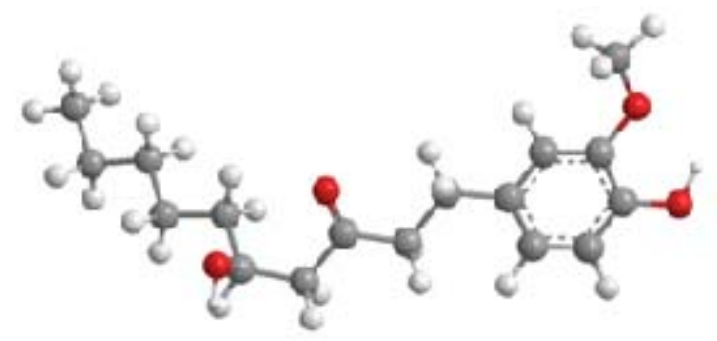

(a)yוlyeivi
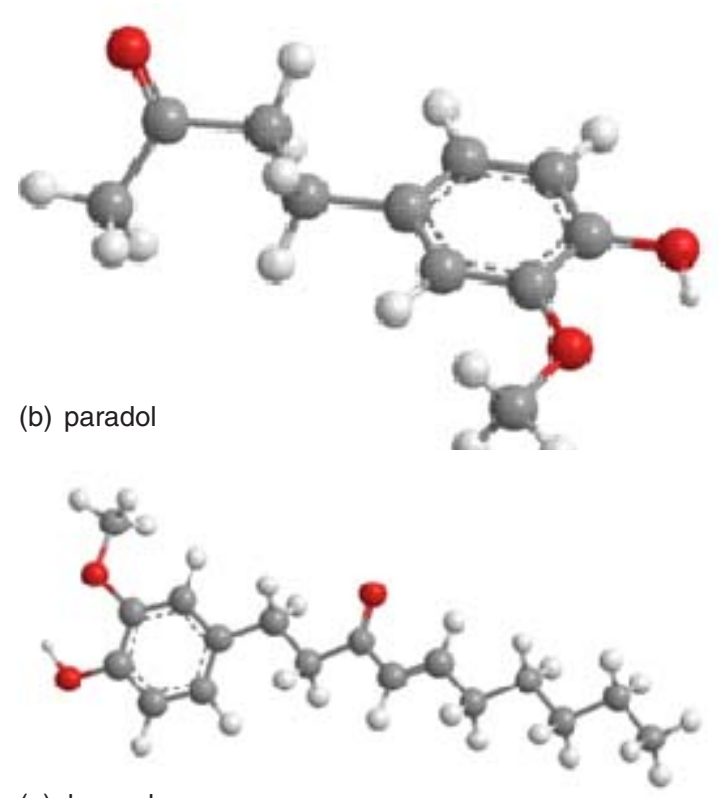

(c)shogaol
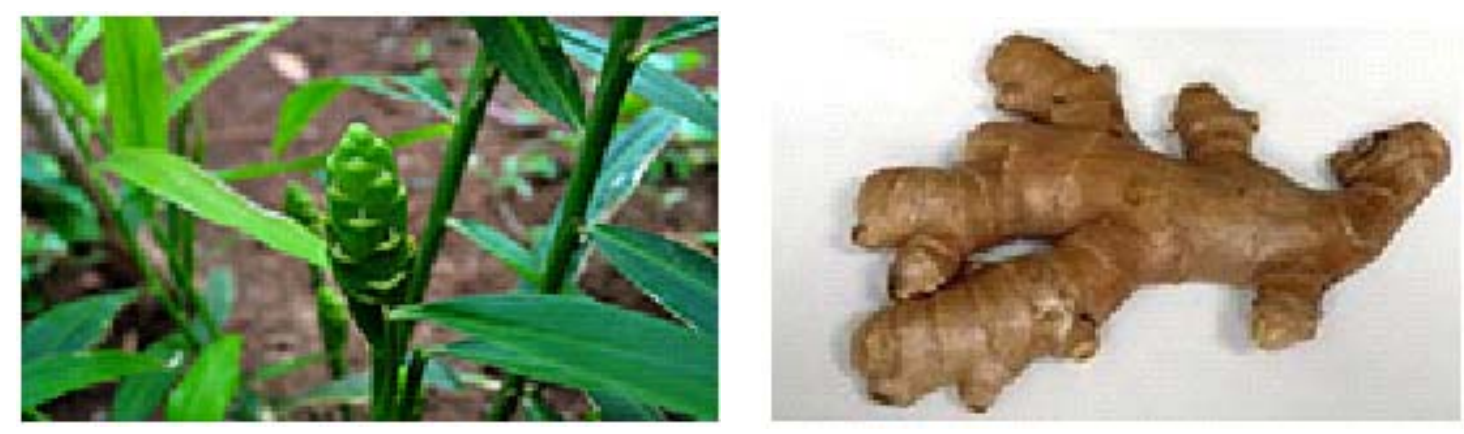

Fig. 1: (a) Ginger Plant with Flower ;(b)Fresh ginger rhizome<smiles>CCCCCC(O)CC(=O)CCc1ccc(Cl)c(OC)c1</smiles><smiles>CC(=O)CCc1ccc(O)c(O)c1</smiles><smiles>C=C(CCCCCCC)CCC1CCC(O)C(CC)C1</smiles>

Fig. 2. Active phenolic compounds of Ginger such as (a)gingerol ;(b) paradol and (c)shogaol. 

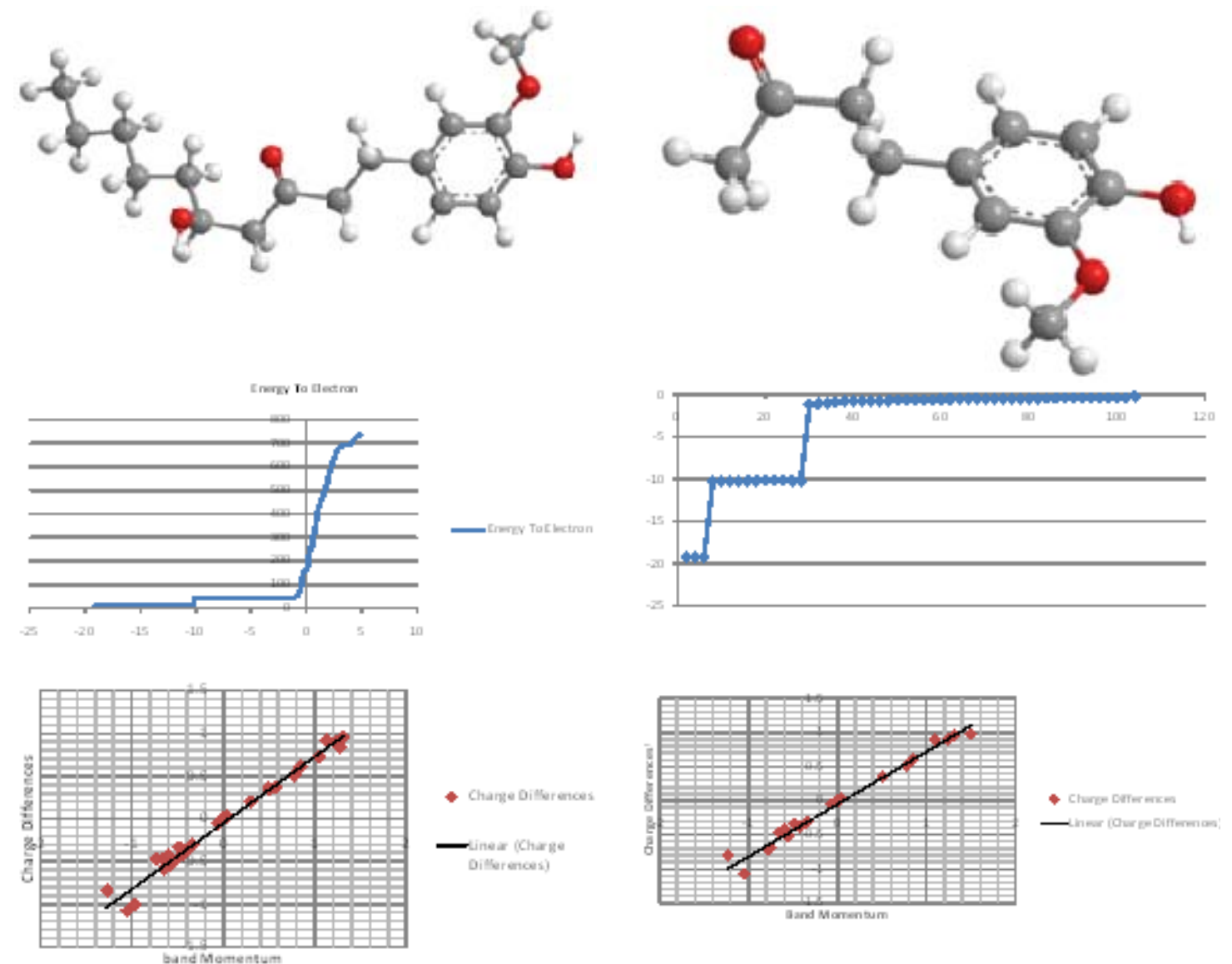

a)

b)
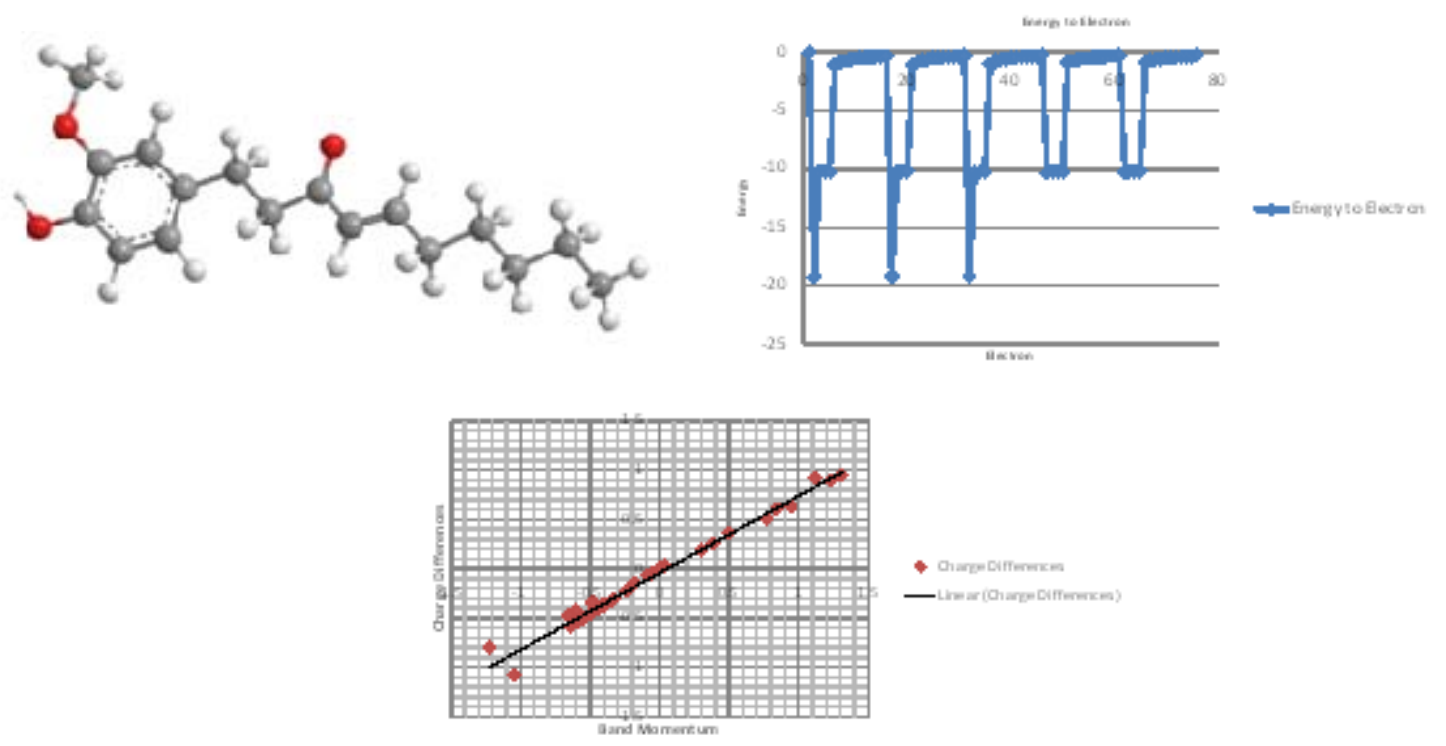

- Chargedifenerces

- Limearichare Differmon

c)

Fig 3. : Variation of charge differences as function of band moumentumand variation energy to electron 

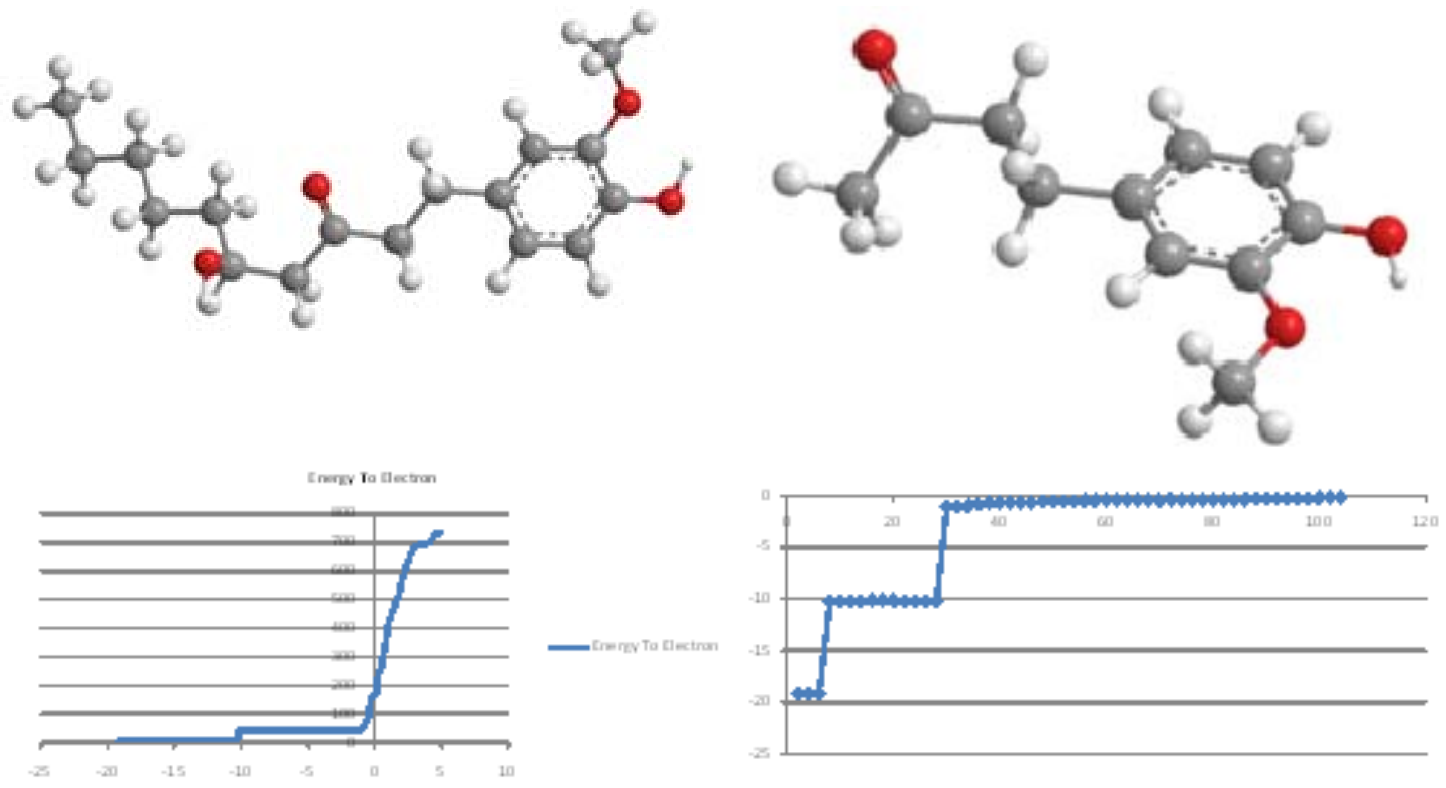

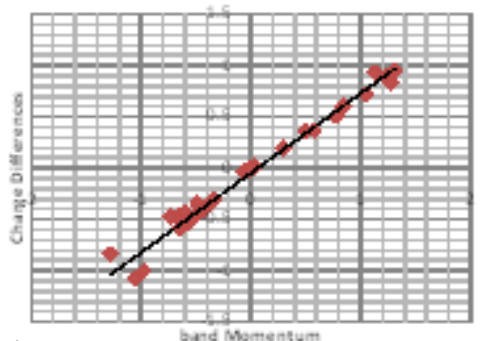

a)

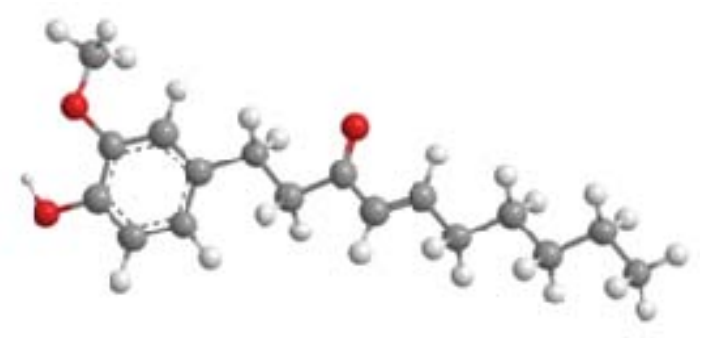

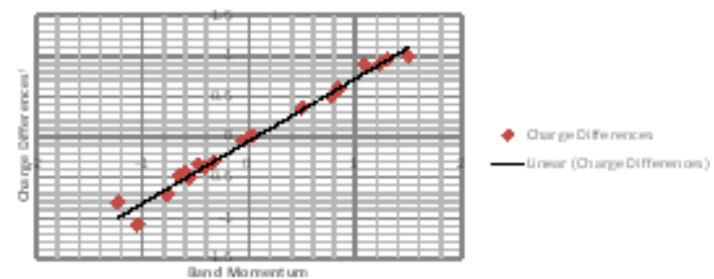

b)

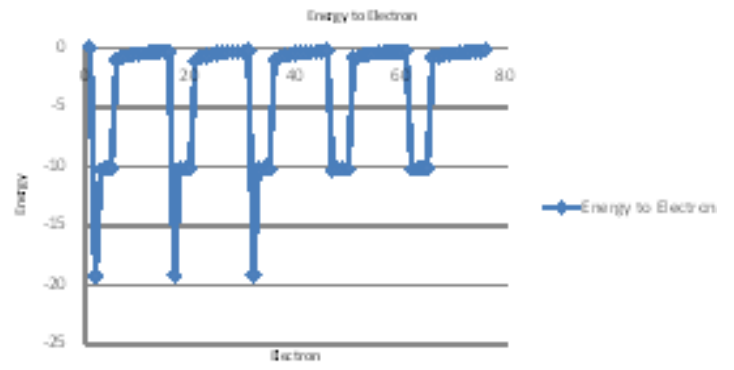

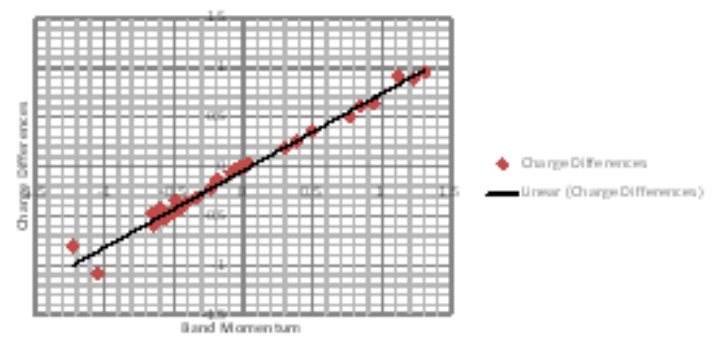

c)

Fig. 4: H NMR and C NMR a,b,c Molecules 

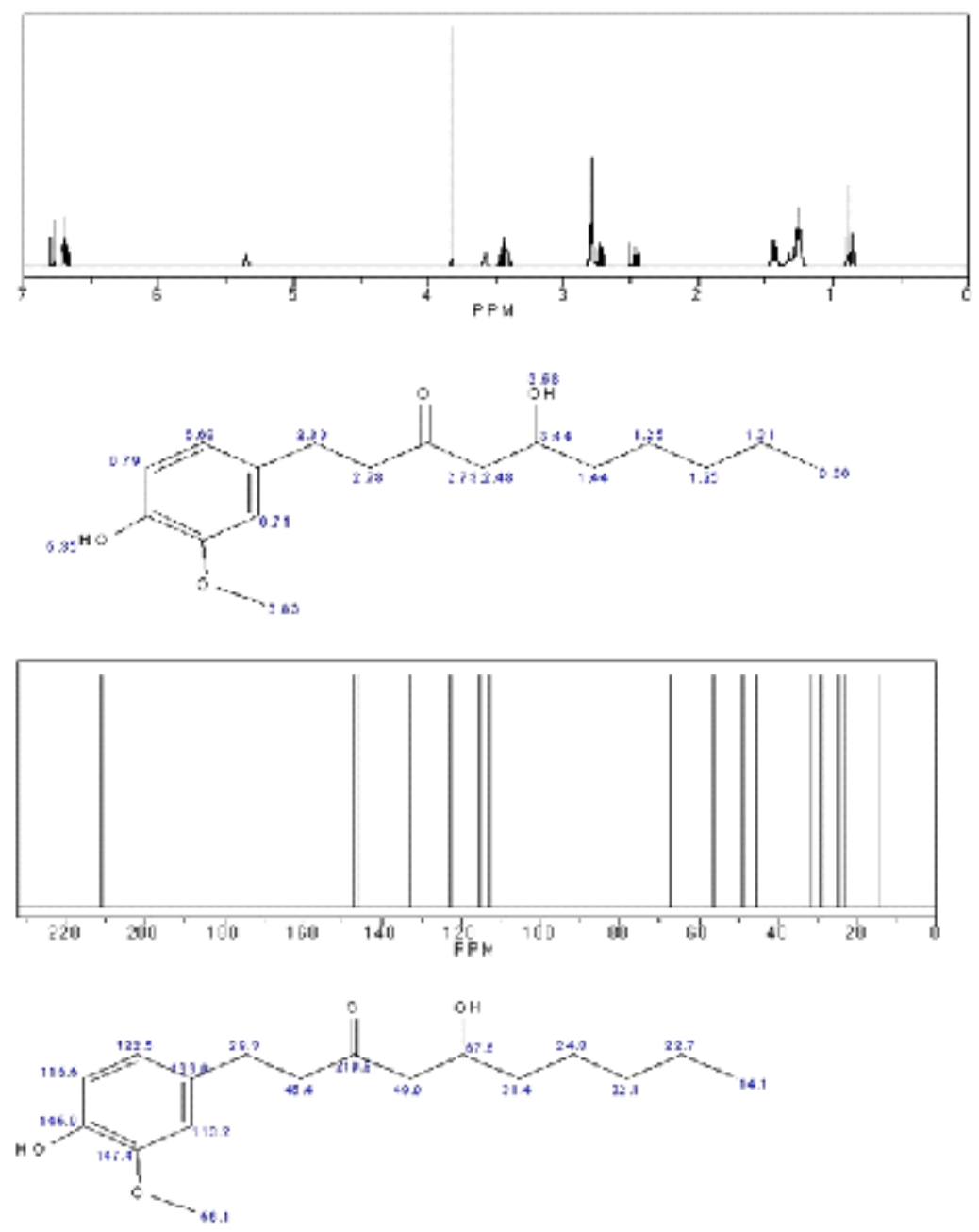

a)
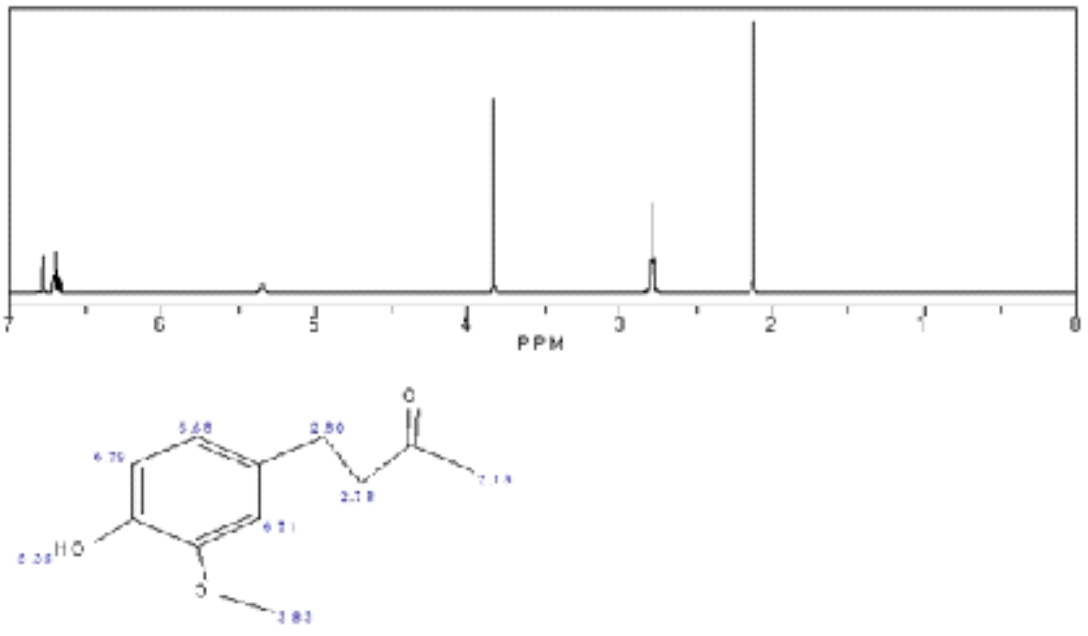


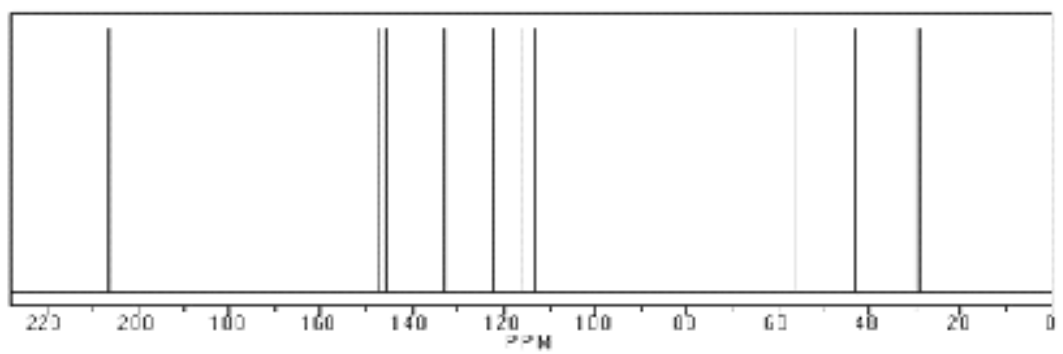

b)
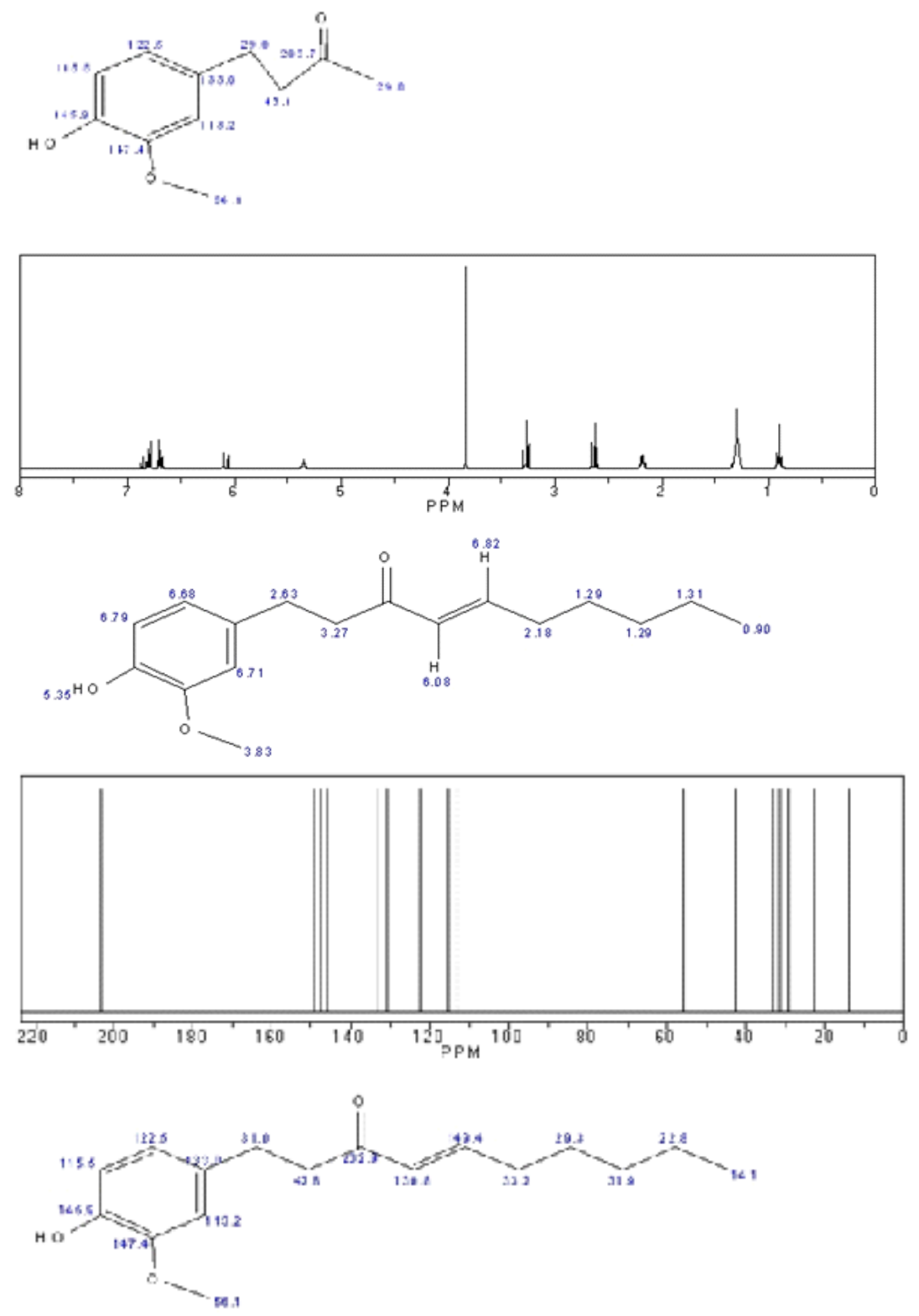

c)

Fig. 6 
We have also emploied an ab initio method to study, check and discussion.

Then, we consider 3 molecular of ginger family and study its behavior using ab initio calculations within Gussian 98 methods for calculation via the (B3LYP-MP2-) with 6-31g*, basis sets. We compare the Gap Energy (E HF ), Dipol Totally ,DET distance matrix values obtained from the present first principles total energy calculations

. Here, we further investigated the roles of Number of atoms, The number of functional groups present in the substitution of, Types of bonds between two atoms, Increased or decreased by the factor ring resonator , (5):The chemical shifts and the factors NMR.by determin all All existing parameters.

In facct, we calculate NMR factors and then compare data and We draw diagrams associated with them According to Fig 4.

\section{RESULTSAND DISCUSSION}

We first consider each molecule with Gussian09 and preoared opt each molculeAs shown in figure 1.Infact in table you observe data for all 3 molecule.
We obtained data NMR molecules according with figure 2 . In Table $a, b$ and $c$ we list various

Parameters and calculated values relevant for the calculations of data NMRand fig 5 shown $\mathrm{H}$ NMR and C NMR. It can be seen variation of charge differences as function of band moumentum and variation energy to electron in the graphs in Fig. 3

Shown in table 1 . There are a variety of $E$ HF,GapEnergy, Totallydipol, det Distance Matrix, which we can exclude as the reason for the observed (1): Number of atoms :(2) The number of functional groups present in the substitution of, (3): Types of bonds between two atoms, (4): Increased or decreased by the factor ring resonator, (5):The chemical shifts and the factors NMR.As above, these effects, which substituted or have a number of different atoms, can exacerbate in other models of molecules ginger. All This may have direct effects on the antioxidant anti-cancer anti-inflammatory, anti-angiogenesis and anti-artherosclerotic properties

\section{ACKNOWLEDGMENT}

I thank support Professor Majid Monajjemi my supervisor, supporter and booster from Islamic Azad University, Science and Research .

\section{REFERENCES}

1. Afzal M, Al-Hadidi D, Menon M, Pesek J, Dhami MS. Ginger: an ethnomedical, chemical and pharmacological review. Drug Metabol Drug Interact. 2001; 18:159-90.

2. Jeyakumar SM, Nalini N, Menon VP. Antioxidant activity of ginger (Zingiberofficinale) in rats fed a high fat diet. Med Sci Res. 1999; 27:341-44().

3. Shukla Y, Singh M. Cancer preventive properties of ginger: A brief review. Food ChemToxicol. 2007; 45:683-90.

4. Hudson EA, Fox LH, Luckett JCA, Manson MM. Ex vivo cancer chemoprevention research possibilities.Environmental Toxicology and pharmacology. 2006; 21:204-14.
5. Huang S, DeGuzman A, Bucana CD, Fidler IJ. Nuclear factor-kappaB activity correlates with growth, angiogenesis, and metastasis of human melanoma cells in nude mice. Clin Cancer Res. 2000; 6:2573-81.

6. Coppola G, Novo S. Statins and peripheral arterial disease: effects on claudication, disease progression, and prevention of cardiovascular events. Arch Med Res. 2007; 38:479-88.

7. M. Monajjemi, F. Naderi, F. Mollaamin, and M. Khaleghian, J. Mex. Chem. Soc. 2012, 56(2), 207-211

8. M. Monajjemi, Struct Chem., 2012; 23: 551580.

9. M. Monajjemi, J.E Boggs, J. Phys. Chem A. 
2013; 117: 1670.

10. M. Monajjemi, V. S. Lee, M. Khaleghian, B. Honarparvar, F.Mollaamin, J. Phys. Chem C., 2010; 114: 15315.

11. MajidMonajjemi, Chemical Physics, 2013; 425: 29-45

12. M. Khaleghian; M. Zahmatkesh; F. Mollaamin ; M. Monajjemi,Fullerenes, Nanotubes, and Carbon Nanostructures, 2011; 19: 251-261.

13. M. Monajjemi, J. Najafpour, \& F. Mollaamin,Fullerenes, Nanotubes, and Carbon Nanostructures, 2013; 21: 213-232.

14. F. Mollaamin, F. Najafi, M. Khaleghian , B. KhaliliHadad\&M.Monajjemi ,Fullerenes, Nanotubes, and Carbon Nanostructures, 2011; 19: 653-667.

15. M. Monajjemi, M. Khaleghian, J Clust Sci., 2011; 22: 673.

16. H. Yahyaei\& M. Monajjemi, Fullerenes, Nanotubes, and Carbon Nanostructures, 2014; 22: 346-361

17. H. Yahyaei, M. Monajjemi, H. Aghaie, and K. Zare, Journal of Computational and Theoretical Nanoscience, 2013; 10(10): 2332-2341.

18. MajidMonajjemi, Robert Wayne, JrandJames E. Boggs, Chemical Physics, 2014; 433: 1-11.

19. T. Ardalan, P. Ardalan\& M. Monajjemi, Fullerenes, Nanotubes, and Carbon Nanostructures, 2014; 22: 687-708.

20. M. Monajjemi, and M. Ahmadianarog, Journal of Computational \& Theoretical Nanoscience 2014; 11(6): 1465-1471.

21. M. Monajjemi, R. Faham \& F. Mollaamin, Fullerenes, Nanotubes, and Carbon Nanostructures, 2012; 20: 163-169.

22. M. Monajjemi ; H. Chegini ; F. Mollaamin ; P. Farahani, Fullerenes, Nanotubes, and Carbon Nanostructures, 2011; 19: 469-482.

23. M. Monajjemi, M. SeyedHosseini\& F. Molaamin, Fullerenes, Nanotubes, and Carbon Nanostructures, 2013; 21: 381-393,

24. M. Monajjemi\& J. Najafpour, Fullerenes, Nanotubes, and Carbon Nanostructures, 22: 575-594, 2014

25. F. Mollaamin, J. Najafpour, S. Ghadami, A. R. Ilkhani, M. S. Akrami, and M. Monajjemi J. Comput. Theor.Nanosci. 11, 1290-1298 (2014)
26. F. Mollaamin , M. Monajjemi\& J. Mehrzad, Fullerenes, Nanotubes, and Carbon Nanostructures, 2014; 22: 738-751.

27. M. Monajjemi , and F. Mollaamin , Journal of Computational and Theoretical Nanoscience, 2012; 9(12): 2208-2214.

28. F. Mollaamin and M. Monajjemi ,Journal of Computational and Theoretical Nanoscience , 2012; 9(4): 597-601.

29. Monajjemi,L.Mahdavian,F,Mollaamin,Bull Chem.Soc.Ethiop ,2008,22(2),1-10.

30. M. Monajjemi ; L. Mahdavian ; F. Mollaamin ; B. Honarparvar, Fullerenes, Nanotubes and Carbon Nanostructures, 2010; 18: 45-55.

31. F. Mollaamin, M.T.Baei, M. Monajjemi, R.Zhiani, B.Honarparvar, Russian Journal of Physical Chemistry A 2008; 82(13): 23542361.

32. M. Monajjemi, N. Karachi \& F. Mollaamin, Fullerenes, Nanotubes, and Carbon Nanostructures, 2014; 22: 643-662.

33. B. Ghalandari, M. Monajjemi, and F. Mollaamin, Journal of Computational and Theoretical Nanoscience, 2011; 8, 1212 1219.

34. M. Monajjemi, B. Honarparvar, S. M. Nasseri, and M. Khaleghian, Journal of Structural Chemistry, 2009; 50, 1, 67-77.

35. M. Monajjemi, M. SeyedHosseini, M. Mousavi \& Z. Jamali, Fullerenes, Nanotubes, and Carbon Nanostructures, 2014; 22: 798-808.

36. R.P. Adams, Identification of Essential Oil Components by Gas Chromatography/ Quadrupole Mass Spectroscopy, Allured Publishing Corp.,Carol Stream, IL, USA, 2004.

37. Monajjemi,M.T.Baei,F.Mollaamin,Russian Journal of Inorganic Chemistry 2008; 53(9): 1430-1437.

38. M. Monajjemi, H. Yamola\& F. Mollaamin, Fullerenes, Nanotubes, and Carbon Nanostructures, 2014; 22: 595-603.

39. M.Monajjemi, S. Afsharnezhad, M.R. Jaafari, T.Abdolahi,A.Nikosade and H. Monajjemi. Russian Journal of physical chemistry A, 2007; 2: 1956-1963.

40. M. Monajjemi, A. Sobhanmanesh, \& F. Mollaamin, Fullerenes, Nanotubes, and Carbon Nanostructures, 2013; 21: 47-63. 